\title{
Autosomal dominant sleep-related hypermotor epilepsy
}

INSERM

\section{Source}

INSERM. (1999). Orphanet: an online rare disease and orphan drug data base. Autosomal dominant sleep-related hypermotor epilepsy. ORPHA:98784

Autosomal dominant nocturnal frontal lobe epilepsy (ADNFLE) is a seizure disorder characterized by intermittent dystonia and/or choreoathetoid movements that occur during sleep. The clusters of nocturnal motor seizures are often stereotyped and brief. 